\title{
De que atividade se fala quando se fala de trabalho?
}

\section{Matheus Bernardo Silva* Ligia Regina Klein ${ }^{* *}$}

\section{Resumo}

A pesquisa que ensejou o presente trabalho, de caráter teórico, vem analisando um conjunto de categorias fundamentais para a Teoria Histórico-Cultural, amplamente recorrentes de forma genérica nos cursos de pedagogia, mas nem sempre tomadas no sentido que lhe confere tal teoria. A recente divulgação da Teoria Histórico-Cultural no campo da educação colocou na pauta dos discursos pedagógicos uma ampla terminologia cujo vigor categorial só se mantém perante a fidelidade ao seu conteúdo. Entretanto, observou-se, no curso da prática docente, que os alunos tendem a empregar certos termos sem, no entanto, discriminar claramente seu sentido, conforme lhes atribuem diferentes perspectivas teóricas. Incorrem, inadvertidamente, em um ecletismo deletério, conferindo significados que, por vezes, são estranhos ou até mesmo contrários aos fundamentos de determinada teoria. O presente artigo analisa a categoria "atividade" na pedagogia escolanovista, contrapondo-a as teorizações de Leontiev, com referência à categoria "trabalho", conforme formulação de Marx.

Palavras-chave: Atividade. Trabalho. Educação.

\footnotetext{
* Doutorando em Educação pela Universidade Estadual de Campinas (UNICAMP). Professor Substituto do Departamento de Teoria e Prática de Ensino da Universidade Federal do Paraná (UFPR).

** Doutorado em Educação pela Pontifícia Universidade Católica de São Paulo (PUC/SP). Pós-doutorado em Educação pela Universidade Estadual de Campinas (UNICAMP). Professora da Universidade Federal do Paraná (UFPR).
} 


\section{Considerações iniciais}

Se o produto do trabalho me é estranho, [se ele] defronta-se comigo como poder estranho, a quem pertence então? Se minha própria atividade não me pertence, é uma atividade estranha, forçada, a quem ela pertence, então?

A outro ser que não eu. Quem é este ser?

Os deuses?

(MARX, 2008, p. 86).

As contribuições da Teoria Histórico-Cultural demoraram a produzir resultados na educação brasileira. Entre as razões, são relevantes a sua tardia difusão entre pesquisadores brasileiros, bem como a assimilação de suas categorias a teorizações estranhas ou mesmo contrárias aos seus fundamentos. O emprego de uma idêntica terminologia não significa identidade de perspectiva teórica, posto que, para além do termo, interessa o conteúdo que se atribui, o qual é inerente ao fundamento em que se enraíza. Assim, deve-se atentar que as categorias da Teoria Histórico-Cultural só podem ser devidamente apreciadas e manejadas nos marcos do materialismo histórico-dialético. A pesquisa que ensejou o presente trabalho, de caráter teórico, busca analisar um conjunto de categorias fundamentais para a Teoria Histórico-Cultural, amplamente recorrentes de forma genérica nos cursos de pedagogia e empregadas por docentes da Educação Básica, mas nem sempre representadas pelo significado específico que lhes confere tal teoria. Nesse sentido, o presente artigo pretende analisar a categoria "atividade", tal como empregada pela Teoria Histórico-Cultural, tendo como referência a categoria “trabalho”, conforme formulação de Marx e Engels (2007).

\section{A atividade nos marcos do escolanovismo}

A noção de atividade já se fazia fortemente presente no ideário do escolanovismo e foi principalmente com o conteúdo atribuído por essa teoria que tal noção se fixou entre os pedagogos. Como preleciona Saviani (2008), a concepção pedagógica nova ou moderna - a "pedagogia escolanovista" - emergiu no século XIX, com o advento do movimento renovador, em contraposição à concepção dita "tradicional”. Ambas as denominações - pedagogia nova e pedagogia tradicional foram cunhadas pelos educadores escolanovistas com o intuito de demarcar a diferença entre elas. Chamou-se, pois, de "tradicional" todas as correntes anteriores, que tinham em comum “[...] uma visão 
filosófica essencialista de homem e uma visão pedagógica centrada no educador (professor), no adulto, no intelecto, nos conteúdos cognitivos transmitidos pelo professor aos alunos, na disciplina e na memorização" (SAVIANI, 2008, p. 169). A concepção escolanovista, por sua vez, engloba várias correntes que têm em comum uma visão filosófica fundamentada na existência, ou seja, na vida e na atividade. Sob tal perspectiva, no trato pedagógico, conforme Saviani (2008, p. 168):

[...] o eixo deslocou-se do intelecto para as vivências; do lógico para o psicológico; dos conteúdos para os métodos; do professor para o aluno; do esforço para o interesse; da disciplina para a espontaneidade; da direção do professor para a iniciativa do aluno; da quantidade para a qualidade; de uma pedagogia de inspiração filosófica centrada na ciência da lógica, para uma pedagogia de inspiração experimental baseada na biologia e na psicologia.

Coerentemente, destaca-se, ainda, como característica comum às correntes da nova pedagogia, o reconhecimento de "[...] caracteres específicos da visão do mundo e da imaginação infantis, dos sentimentos da criança e da sua actividade" (SUCHODOSLKI, 1984, p. 84). A partir dessa premissa, passou-se a atribuir uma importância marcante à atividade da criança, bem como às suas necessidades e seus interesses. Ademais, ainda segundo Suchodolski (1984, p. 85-86):

A atenção dirigida às diferentes particularidades da psicologia da criança e a tendência para basear o esforço educativo sobre a atividade da própria criança deviam naturalmente contribuir para pôr em relevo o problema da individualidade. Ao passo que a teoria pedagógica tradicional era aplicada à "criança em geral" tentava-se agora uma diferenciação levada ao máximo. Como dizia Claparède, a escola devia funcionar 'por medida'.

Uma tal concepção se assentava no pressuposto de que a criança e o seu mundo apresentavamse como inteiramente distintos dos adultos e do mundo destes, de modo que a educação se resumiria a ser expressão da vida da criança, aliada a seu cuidado. Essa perspectiva pedocêntrica defrontou-se, em breve, com o problema da passagem ao universo adulto, derivando em correntes de desenvolvimento espontâneo, por um lado, e de adaptação, por outro. Não obstante as peculiares respostas que deram à questão, elas confluem na convicção individualista de que "[...] para o homem, a história social dos seres humanos não tem importância constitutiva" (SUCHODOSLKI, 1984, p. 94).

É nessa perspectiva individualista, seja pedocêntrica, seja adaptativa, portanto, incontaminada pela história social, que se compreende a atividade sob as teorizações escolanovistas. 


\section{Trabalho: a atividade humana na perspectiva marxista}

Em oposição à hegemonia do pensamento escolanovista, cuja expressão se renova e fortalece com a difusão, no Brasil, do construtivismo piagetiano, setores da psicologia e da educação aprumam seus argumentos de resistência buscando apoio nos princípios da Teoria Histórico-Cultural, que se inscreve nos marcos do materialismo histórico-dialético, tal como elaborado por Marx e Engels e posteriores aprofundamentos de outros teóricos marxistas, como Lênin, Lukács e Gramsci.

Para o adequado entendimento das categorias manejadas pelos pesquisadores da Teoria Histórico-Cultural é imprescindível a compreensão dos fundamentos da teoria marxista, em especial a determinação ontológica do trabalho na constituição do gênero humano.

De início, convém lembrar a radical diferença entre a atividade meramente animal e a atividade propriamente humana.

Conforme a lição de Luria (1979), o comportamento meramente animal apresenta três traços fundamentais: primeiro, que todo comportamento individualmente variável do animal, mesmo o mais complexo, conserva sua ligação com os motivos biológicos e não pode ultrapassar-lhes os limites; segundo, o comportamento de todo animal é sempre determinado por estímulos imediatamente perceptíveis ou por vestígios da experiência anterior, não podendo ocorrer à margem desses estímulos e vestígios, muito menos entrando em conflito com eles; finalmente, o terceiro traço consiste nas limitações das fontes do comportamento do animal. Podem ser fonte de comportamento do animal os programas alicerçados na sua experiência de espécie, que se transmitem em códigos hereditários, comportamento instintivo, ou aqueles que se formam na experiência imediata de dado indivíduo, comportamento individualmente variável ou reflexivo-condicionado. Os animais não têm nenhuma possibilidade de assimilação da experiência alheia e de um indivíduo transmiti-la assimilada a outro indivíduo e muito menos de transmitir a experiência formada em várias gerações.

Analisando a atividade propriamente humana - a atividade consciente do homem - ver-se-á o quanto se distingue, ao ultrapassar esses três traços que constituem as peculiaridades fundamentais de todo comportamento animal, posto que outras são as determinações da atividade humana. Para Marx (2008), o trabalho é a atividade especificamente humana, posto que realiza a existência do sujeito, enquanto gênero, seja ao produzir condições de existência, seja ao produzir novas necessidades tipicamente humanas. A realização das necessidades da existência (comer, beber etc.) se apresenta como um processo de intercâmbio material do indivíduo com a natureza.

PERSPECTIVA, Florianópolis, v. 34, n. 1, p. 305-318, jan./abr. 2016

http://www.perspectiva.ufsc.br 
Na condição animal, tal intercâmbio se dá de modo duplamente natural: os meios de existência são retirados da natureza, tal como ela os produz e são retirados com o concurso dos meios naturais do organismo (garras, presas, patas, asas, guelras, etc., a depender da espécie e de suas necessidades vitais). As espécies - muito raras - que se valem de algum tosco instrumento, tal como um galho ou uma pedra, por exemplo, não obstante valerem-se de algo externo ao próprio organismo para agirem sobre a natureza, não logram transformar, senão funcionalmente, elementos naturais dados. Vale dizer: o galho, a pedra, ou outro elemento utilizado não chegam a sofrer qualquer transformação: o galho não é apontado, a pedra não é polida (KLEIN; KLEIN, 2011, p. 27).

Se a existência de indivíduos vivos é a primeira condição para a história, as condições do intercâmbio dos indivíduos com a natureza, em primeira instância valendo-se de suas forças naturais, aponta a segunda condição para a compreensão da história humana: "a constatação da organização física dos indivíduos e, por meio dela, sua relação dada com o restante da natureza" (MARX; ENGELS, 2007, p. 87).

Com efeito, a história humana é a história do processo de transformação dessa relação com a natureza, daí a afirmação de Marx e Engels (2007, p. 87): “Toda historiografia deve partir desses fundamentos naturais e de sua modificação pela ação dos homens no decorrer da história". Se, inicialmente, essa relação é determinada exclusivamente pela organização física dos indivíduos, no curso da história o homem a modifica por meio do trabalho, ou seja, passa a agir cooperativamente e a produzir tecnologias que potencializam indefinidamente os recursos daquela original organização física, criando o "gênero humano" como aquele gênero das "infinitas possibilidades".

A condição propriamente humana, portanto, conforme detalham Klein e Klein (2011), é aquela em que os homens alteram radicalmente sua forma de relação com a natureza, no processo de produção da existência, graças aos mediadores por eles criados para potencializar essa relação. Esses mediadores vão desde instrumentos rudimentares até a mais apurada tecnologia, bem como as várias formas de cooperação, ou relações sociais.

No curso da história humana, essas condições de relação dos homens com a natureza e dos homens entre si se desenvolvem constantemente, ainda que em ritmos diversos, em função das necessidades que emergem do modo de suprir as próprias necessidades anteriores. Na dicção de Marx e Engels (2007, p. 33):

O primeiro ato histórico é, pois, a produção dos meios para a satisfação dessas necessidades, a produção da própria vida material, e este é, sem dúvida, um ato histórico, uma condição fundamental de toda a história, que ainda hoje, assim como há 
milênios, tem de ser cumprida diariamente, a cada hora, simplesmente para manter os homens vivos.

[...] O segundo ponto é que a satisfação dessa primeira necessidade, a ação de satisfazê-la e o instrumento de satisfação já adquirido conduzem a novas necessidades - e essa produção de novas necessidades constitui o primeiro ato histórico.

Não só os mediadores citados - instrumentos e cooperação - desempenham um papel fundamental nesse processo de potencialização das condições de relação com a natureza e relações com os outros homens, mas são igualmente relevantes os recursos psicológicos de interação com o mundo exterior, criados sob a necessidade do trabalho, vale dizer, sob a necessidade daquelas mesmas relações dos homens com a natureza e dos homens entre si, conforme esclarecem Klein e Klein (2011).

Embora seja, primitivamente, “[...] mera consciência do meio sensível mais imediato e consciência do vínculo limitado com outras pessoas e coisas exteriores ao indivíduo que se torna consciente [...]" (MARX; ENGELS, 2007, p. 35, grifos dos autores), a consciência é, desde o início, um produto social que somente se torna possível pelo concurso da linguagem, a partir da demanda colocada pela cooperação e pela produção/reprodução dos meios de existência. A consciência - o psiquismo - e seus recursos se desenvolvem no fluxo do desenvolvimento dessas demandas. $O$ psiquismo é, portanto, eminentemente material, pois se vale da organização física do cérebro, potencializado pela linguagem - de início, manifestada "[...] sob a forma de camadas de ar em movimento, de sons [...]" (MARX; ENGELS, p. 34), em resposta às demandas da vida material.

Eis, em suma, o conteúdo que Marx e Engels (2007) atribuem à “atividade humana": é trabalho, ou seja, atividade demandada por necessidades vitais, por meio da qual os homens ao mesmo tempo criam condições de existência - recursos potencializadores de suas relações com a natureza e entre si e são por elas criados. Pelo trabalho, os homens elevam-se, dos limites da espécie, à condição de gênero.

Essa concepção de atividade assiste ontologicamente o próprio conceito de "homem em geral" e sua “natureza” histórica, como esclarece Michael Löwy (1978, p. 55, tradução nossa, grifos do autor):

O conceito de "homem em geral" de O Capital é o de um animal social que produz utilizando instrumentos, segundo um "projeto", vale dizer, um fim consciente que preexiste idealmente em sua imaginação, o qual distingue o pior engenheiro da melhor abelha, etc. Significa isto, acaso, que existe uma "natureza humana eterna"? Não, posto que Marx precisa nesta mesma passagem que "ao mesmo tempo que desse modo atua sobre a natureza exterior e a transformar, transforma sua própria natureza". 
É sob tal concepção de atividade, portanto, e somente sob ela, que se pode entender e manejar adequadamente tal categoria nos fundamentos da Teoria Histórico-Cultural, como veremos na análise da contribuição de Leontiev.

\section{Apontamentos sobre a atividade humana: contribuições da Teoria da Atividade em Leontiev}

Pelo acúmulo teórico baseado no materialismo histórico-dialético, podemos conceber que a atividade é a categoria central desse aporte filosófico. Resgatando a análise anterior sobre a diferença entre a atividade animal e a atividade humana, entre outros elementos, pode-se acrescentar, de acordo com Marx (2008, p. 84-85, grifos do autor), que "O homem faz da sua atividade vital mesma um objeto da sua vontade e da sua consciência. Ele tem atividade vital consciente. [...] A atividade vital consciente distingue o homem imediatamente da atividade vital animal". O autor ainda argumenta que "O engendrar prático de um mundo objetivo, a elaboração da natureza inorgânica é a prova do homem enquanto um ser genérico consciente, isto é, um ser que se relaciona com o gênero enquanto sua própria essência ou [se relaciona] consigo enquanto ser genérico" (MARX, 2008, p. 84-85, grifo do autor).

Leontiev (2007, p. 91) explicita que "Ao contrário dos animais, o homem tem outro tipo de experiência: a experiência histórico-social. Esta não coincide com a experiência da espécie, biologicamente herdada, nem com a experiência individual, apesar de frequentemente se confundir com esta".

O conceito de atividade é uma das principais categorias para o estudo do desenvolvimento do psiquismo. Trata-se, portanto, de um elemento de extrema pertinência para o campo da Teoria Histórico-Cultural. De acordo com Leontiev (1978a) e Asbahr (2005), a ideia de analisar e de aprofundar a atividade como método da psicologia científica do homem surge já nos primeiros trabalhos de Vigotski, quando são introduzidos os conceitos de instrumento, de operações instrumentais, de motivo etc. No entanto, podemos encontrar em Leontiev a sistematização, a ênfase dada nos estudos centrados na pesquisa da atividade humana, ou seja, no conjunto de relações do indivíduo mediado por outros indivíduos e por instrumentos. "Foi [...] [ele] quem sistematizou o conceito de atividade, fundando a teoria psicológica geral da atividade. Esse conceito desempenha as 
funções de princípio explicativo dos processos psicológicos superiores e de objeto de investigação" (ASBAHR, 2005, p 109).

Apoiando-se na filosofia marxista, Leontiev (1979 apud SERRÃO, 2006, p. 104-105) afirma que a atividade humana surge nas necessidades objetivas e subjetivas impostas ao indivíduo no decorrer de sua história: “[...] a atividade é a unidade não aditiva, molar da vida, para o sujeito material e corporal. [...] A atividade não é uma reação ou um agregado de reações, mas um sistema que possui estrutura, transformações internas e desenvolvimento próprios”.

Seguindo as orientações do autor, concorda-se que:

A primeira condição de toda a actividade é uma necessidade. Todavia, em si, a necessidade não pode determinar a orientação concreta de uma actividade, pois é apenas no objecto da actividade que ela encontra a sua determinação: deve, por assim dizer, encontrar-se nele. Uma vez que a necessidade encontra a sua determinação no objecto (se objectiva nele), o dito objecto torna-se motivo da atividade, aquilo que o estimula. (LEONTIEV, 1978b, p. 107-108).

A atividade pode estar em um nível superior e/ou natural. Apenas o indivíduo - partícipe do gênero humano - possui necessidades superiores que são encontradas no âmbito social. Contudo, com o acréscimo do modo de produção capitalista, da propriedade privada, o indivíduo passou a realizar suas necessidades vitais para poder atuar. Contrariamente da atividade humana primitiva, na qual a atividade era efetivada coletivamente, ou seja, atividade de um bando (DUARTE, 1999).

O surgimento das necessidades gera sempre o motivo: “[...] o conceito de atividade está necessariamente unido ao conceito de motivo. Não há atividade sem motivo; a atividade 'não motivada' não é uma atividade carente de motivo, se não uma atividade com um motivo subjetivo e objetivamente oculto" (LEONTIEV, 1978a, p. 82).

Outro elemento constituinte da atividade são as ações: "Uma ação é um processo cujo motivo não coincide com o seu objecto (isto é, com aquilo que visa), pois pertence à actividade em que entra a acção considerada" (LEONTIEV, 1978b, p. 297-298). Duarte (1999, p. 84) explicita que, quando a atividade se fragmenta em ação, não há mais uma coincidência entre o objeto no qual o indivíduo age e o motivo por que está agindo, ou seja, “[...] o fim de uma ação, seu resultado imediato, não coincide com o motivo, com a necessidade que leva o homem a agir".

A operação é um elemento que Leontiev (1978b) também considera como constitutivo da atividade. O soviético afirma que “[...] quando o fim de uma acção entra numa segunda acção, enquanto condição de sua realização, ela transforma-se em meio de realização da segunda acção, por 
outras palavras, torna-se operação consciente" (LEONTIEV, 1978b, p. 104). A operação torna-se um mecanismo para poder efetivar tal ação no bojo de uma determinada atividade.

Em suma, Asbarh (2005, p. 110) menciona que "Necessidade, objeto e motivo são componentes estruturais da atividade. Além desses, a atividade não pode existir senão pelas ações, constituindo-se pelo conjunto subordinadas a objetivos parciais advindos do objetivo geral".

Duarte (2002, p. 285) expõe que, para Leontiev:

[...] a atividade humana possui sempre algum motivo. Quando essa atividade passa a ser composta de unidades menores, as ações, isso quer dizer que cada uma das ações individuais componentes da atividade coletiva deixa de ter uma relação direta com o motivo da atividade e passa a manter uma relação indireta, mediatizada, com aquele motivo.

Embora cientes de que a apropriação desse elemento complexo e importante da formação humana necessite de mais argumentos para o seu total entendimento, ressaltamos que a intenção, neste texto, foi a de elucidar sucintamente os elementos estruturais da atividade humana, a fim de que possamos fazer uma reflexão sobre ela no interior do modo de produção capitalista.

Duarte (2002, p. 284) nos alerta para que analisemos a atividade humana no sentido de os “[...] processos de alienação produzidos pelas atividades que dão o sentido (ou o sem-sentido) da vida dos seres humanos na sociedade capitalista". Ou seja, ignorar essa questão faz com que a Teoria da Atividade e as contribuições de Leontiev caiam em um "vazio" sem sentido, sem um potencial crítico.

Leontiev (2007, p. 91, grifo nosso) argumenta:

As conquistas do desenvolvimento histórico humano são consolidadas e transmitidas de uma geração para outra de maneira particular, e precisamente de maneira exotérica, externa. Esta nova forma de acumulação das experiências filogenética (ou, mais concretamente, histórico-social) surgiu porque a forma específica da atividade do homem é a atividade produtiva. Ou seja, a atividade fundamental dos homens é o seu trabalho.

Baseando-se nos subsídios de Marx, o autor sustenta a sua conclusão:

A atividade humana (tanto mental como material), tal como se manifesta no processo de produção, está cristalizada no produto; o que num extremo se manifesta como ação, movimento, no outro extremo, o do produto, transforma-se numa propriedade estavelmente definida. A mesma transformação é um processo no qual se produz uma objetivação das capacidades humanas: as conquistas histórico-sociais da espécie. Qualquer objeto criado pelo homem - desde o mais simples utensílio à moderníssima máquina calculadora eletrônica - realiza tanto a experiência histórica do gênero humano como as capacidades intelectuais formadas nesta experiência. $\mathrm{O}$ mesmo pode 
comprovar-se com maior clareza na linguagem, na ciência, nas obras de arte. (LEONTIEV, 2007, p. 92).

Uma das características da atividade humana é a objetividade, que pode ser efetivada no interior do atual modo de sociabilidade em alguns momentos: (1) atividade humana como atividade consciente; (2) atividade humana como trabalho dos homens sobre a natureza; (3) atividade humana como trabalho dos homens sobre os homens (MARX; ENGELS, 2007).

A principal diferença para a comunidade primitiva é que nela os sentidos dos fenômenos reais coincidiam totalmente com as significações fundamentadas socialmente e concretizadas pela linguagem. "A propriedade coletiva colocava os homens em relações idênticas em relação aos meios e frutos da produção, sendo estes últimos, portanto, reflectidos de maneira idêntica na consciência individual e na consciência colectiva” (LEONTIEV, 1978b, p. 113-114).

É, então, somente no surgimento e no desenvolvimento da divisão social e técnica do trabalho, nas novas vinculações de propriedade privada que se poderia "[...] actuar de modo que a estrutura inicial da consciência cedesse lugar a uma nova, respondendo às novas condições sócio-económicas da vida humana" (LEONTIEV, 1978b, p. 114). A estruturação da consciência baseada nessa condição social de vida fez com que ocorresse uma ligação entre os componentes da consciência, os sentidos e as significações.

Lembramos que a consciência e a atividade humana são para a Teoria Histórico-Cultural elementos fundamentais e devem ser compreendidos em uma unidade dialética: “A consciência é o produto subjetivo da atividade dos homens com os outros homens e com os objetos; assim, a atividade constitui a substância da consciência [...]” (ASBAHR, 2005, p. 110).

Leontiev (1978b, p. 120) expõe que “A primeira transformação da consciência, engendrada pelo desenvolvimento da divisão social do trabalho, consistiu, portanto, no isolamento da actividade intelectual e teórica”. A segunda é a mudança da estrutura interna:

A grande massa de produtores separou-se dos meios de produção e as relações entre os homens transformaram-se cada vez mais em puras relações entre as coisas que se separam ("se alienam") do próprio homem. O resultado é que a sua própria actividade deixa de ser para o homem o que ela é verdadeiramente. (LEONTIEV, 1978b, p. 120121).

Observamos, portanto, que a segunda mudança apresenta-se de extrema importância para compreendermos o desenvolvimento de nossa consciência e o papel exercido pelas atividades - como Duarte (2002) nos alertou em seu trabalho - no seio da sociedade de classes, em que a alienação toma 
tamanha dimensão em nossas atividades. Leontiev (1978b, p. 121, grifo nosso) assevera essa questão da alienação no atual modo societal com uma pertinente passagem:

Esta "alienação" é criada pelo desenvolvimento das formas de propriedade e das relações de troca. Na origem, o trabalho do homem não estava separado das suas condições materiais. $\mathrm{O}$ homem encontrava-se em perfeita relação de unidade natural com as condições objectivamente necessárias à vida. Mas o desenvolvimento das forças produtivas desagrega inevitavelmente esta relação, o que se traduz pelo desenvolvimento das formas de propriedade. A ligação inicial do trabalhador à terra, aos instrumentos de trabalho, ao próprio trabalho encontra-se destruída. Finalmente, a grande massa dos produtores transforma-se em operários assalariados, cuja única propriedade é a sua capacidade de trabalho. As condições objectivas da produção opõem-se-lhes doravante enquanto propriedade estranha. Para viver, para satisfazer as suas necessidades vitais, vêem-se, portanto, coagidos a vender a sua força de trabalho, a alienar o seu trabalho. Sendo o trabalho o conteúdo mais essencial da vida, devem alienar o conteúdo da sua própria vida.

O modo de produção capitalista, por meio da alienação - do estranhamento -, faz com que ocorra na atividade humana uma desarmonia entre o resultado dessa atividade e o seu motivo: "[...] o conteúdo objectivo da actividade não concorda agora com o seu conteúdo subjectivo, isto é, com aquilo que ela é para o próprio homem" (LEONTIEV, 1978b, p. 122).

Sob essa forte atuação da alienação na formação da consciência humana, Leontiev (1978b) examina a ligação da alienação com a atividade humana, "entrando" na vida do trabalhador numa dupla via dialética - de maneira positiva e de maneira negativa:

Negativamente, porque o trabalho lhe toma uma parte da vida, pois fazer pela não é viver. A vida começa para ele onde acaba esta actividade, à mesa, em casa, na cama. Positivamente, sob duas relações. Primeiro, enquanto meio de actividade. Ele constitui a riqueza real do aspecto "técnico" da sua vida, riqueza em conhecimentos, em hábitos, em saber-fazer que lhe é necessário possuir para efectuar o seu trabalho. Segundo, enquanto condição de enriquecimento da sua vida por um conteúdo novo, muito diferente do da sua actividade alienada, mas, todavia, criada por ela. (1978b, p. 125126, grifos do autor).

Eis aí a interferência assídua e avassaladora da alienação em nossas atividades. Duarte (2002, p. 286), baseando-se em Leontiev, expõe "que na sociedade capitalista opera-se uma ruptura alienada e alienante entre o significado da ação do operário e o sentido que essa tem para ele, ou seja, uma ruptura entre o conteúdo da ação do operário e o motivo pelo qual o operário age”. 
A essas contradições não se obtêm explicações no seio das teorizações positivistas e idealistas, daí elas somente serem enfrentadas no âmbito de uma concepção afirmativa da historicidade dialética do real.

\section{Considerações finais}

Consideramos, então, que é por esse contexto social que a atividade humana se efetiva na sociedade hodierna e que as proposições pedagógicas devem tomar essas contradições como elemento fundamental para suas intervenções. Todavia, ao analisarmos os posicionamentos ideológico/ontológico/epistemológico do escolanovismo, observamos que não há uma preocupação e uma formulação pedagógica consubstanciada e preocupada com o papel social objetivo da atividade humana. Ao contrário, os pressupostos do escolanovismo aviltam totalmente essa articulação da atividade humana, tal como se realiza na atual sociedade de classes, posto que apenas atribuem sentido às atividades singulares de cada indivíduo, enfatizando apenas o desenvolvimento espontâneo e adaptativo, ou seja, contribuindo veementemente para a efetivação da atividade humana alienada, totalmente estranhada, que se contrapõe ao indivíduo concreto. Tal interpretação impossibilita uma análise e intervenção na conjuntura histórico-social contemporânea.

É nesse contexto que as teorizações materialista-históricas, e no caso da educação, especialmente a Teoria Histórico-Cultural, avultam em possibilidades. Cabe zelar para que suas fecundas categorias não sejam esvaziadas de sentido, ao serem assimiladas, como vêm sendo, à terminologia de tradição a-histórica, seja de natureza metafísica, seja de natureza positivista. Aos golpes da ideologia dominante cabe opor a resistência dos mais legítimos interesses da classe trabalhadora. É nesse sentido que o presente artigo pretendeu apontar uma direção, posto que, afinal, ainda que alienado, confrontando-se como "força estranha" com o trabalhador, o trabalho, atividade propriamente humana, é, sempre, condição de existência da humanidade, confiada ao produtor direto.

\section{REFERÊNCIAS}

ASBAHR, Flávia da Silva Ferreira. A pesquisa sobre a atividade pedagógica: contribuições da teoria da atividade. Revista Brasileira de Educação, Rio de Janeiro, n. 29, p. 108-119, maio/jun. 2005.

DUARTE, Newton. A individualidade para-si: contribuição a uma teoria histórico-social da formação do indivíduo. 2. ed. Campinas, SP: Autores Associados, 1999. 
DUARTE, Newton. A teoria da atividade como uma abordagem para a pesquisa em educação.

Perspectiva, Florianópolis, v. 20, n. 2, p. 279-301, jul./dez. 2002.

KLEIN, Lígia Regina; KLEIN, Bianca Larissa. Ontologia humana e trabalho alienado. In:

VENDRAMINI, Célia Regina; MACHADO, Ilma Ferreira (Org.). Escola e movimento social:

experiências em curso no campo brasileiro. São Paulo: Expressão Popular, 2011. p. 23-42.

LEONTIEV, Alexei N. Actividad, conciencia y personalidad. Buenos Aires: Ediciones Ciencias del Hombre, 1978a.

LEONTIEV, Alexei N. O desenvolvimento do psiquismo. Lisboa: Livros Horizonte, $1978 \mathrm{~b}$.

LEONTIEV, Alexei N. Os princípios do desenvolvimento mental e o problema do atraso mental. In: LEONTIEV, Alexei N. et. al. (Org.). Psicologia e pedagogia: bases psicológicas da aprendizagem e do desenvolvimento. 4. ed. São Paulo: Centauro, 2007. p. 87-105.

LÖWY, Michael. Dialectia y revolucion. Cidade do México: Siglo Veintiuno, 1978.

LURIA, Alexander R. Curso de psicologia geral. Rio de Janeiro: Civilização Brasileira, 1979.

MARX, Karl. Manuscritos econômico-filosóficos. São Paulo: Boitempo, 2008.

MARX, Karl; ENGELS, Friedrich. A ideologia alemã. São Paulo: Boitempo, 2007.

SAVIANI, Dermeval. A pedagogia no Brasil: história e teoria. Campinas, SP: Autores Associados, 2008.

SERRÃO, Maria Isabel Batista. Aprender a ensinar: a aprendizagem do ensino no curso de pedagogia sob o enfoque histórico-cultural. São Paulo: Cortez, 2006.

SUCHODOSLKI, Bogdan. A pedagogia e as grandes correntes filosóficas: pedagogia da essência e a pedagogia da existência. Lisboa: Livros Horizonte, 1984. 


\section{What we talk about when we talk about work?}

\begin{abstract}
The research that led to this study, of theoretical character, has been analyzing a set of categories which are fundamental to the historical-Cultural Theory, widely and generically recurrents in pedagogy courses, but not always taken to giving it such a theory. The recent disclosure of the historical-Cultural Theory in the education field has placed on the agenda of educational speeches a wide terminology whose categorical force stands only before fidelity to its contents. However, it was noted, in the course of teaching practice, students tend to use certain terms without, however, clearly discriminate their sense, as they have different theoretical perspectives. They inadvertently incur in a deleterious eclecticism, with meanings that sometimes are strangers or even contrary to the fundaments of a particular theory. The present work analyzes the category "activity" in New School pedagogy, opposing it to Leontiev's theories, with reference to the category of work, according to Marx's formulation.
\end{abstract}

Keywords: Activity. Work. Education.

\section{Cuál comprensión de actividad cuando se habla de trabajo?}

\section{Resumen}

La investigación que condujo este estudio, de carácter teórico, procura analizar un conjunto de categorías que son fundamentales para la Teoría Histórico Cultural, ampliamente utilizada de un modo genérico en los cursos de pedagogía, pero no siempre en el sentido en que la presente teoría pregona. La reciente divulgación de la Teoría Histórico Cultural en el campo de la educación ha colocado en la agenda de los discursos educativos una amplia terminología cuya relevancia se encuentra en la fidelidad a su contenido. Sin embargo, se observó, en el transcurso de la práctica docente que los estudiantes tienden a emplear ciertos términos sin discriminar claramente su sentido, ya que existen diferentes perspectivas teóricas. Incurren, así, a un eclecticismo perjudicial, otorgando significados que a veces son extraños o incluso contrario a los fundamentos de la teoría particular. El presente trabajo analiza la categoría "actividad" en la pedagogía de la escuela nueva [escolanovista], en contraposición de la teorización realizada por Leontiev, con referencia a la categoría 'trabajo', a partir de la concepción de Marx.

Palabras claves: Teoría Histórico Cultural. Actividad. Trabajo. Educación.

Enviado em: 29/4/2014

Aprovado em: 21/7/2015
Ligia Regina Klein

E-mail:1r.klein@uol.com.br
Matheus Bernardo Silva

E-mail: matheusbernardo25@gmail.com 